\title{
Evaluation of postoperative pain in closure versus non-closure of parietal peritoneum at caesarean section
}

\author{
Avantika Sharma $^{1}$, Nupur Hooja ${ }^{1 *}$, Apoorv Shastri ${ }^{2}$, Brijesh Dadhich $^{1}$, Richa Manish ${ }^{1}$
}

${ }^{1}$ Department of Obstetrics and Gynecology, SMS, Medical College, JLN Marg, Jaipur, Rajasthan, India

${ }^{2}$ Department of Surgery, RNT Medical College, Udaipur, Rajasthan, India

Received: 28 February 2017

Accepted: 31 March 2017

\author{
*Correspondence: \\ Dr. Nupur Hooja, \\ E-mail: nupurhooja@gmail.com
}

Copyright: () the author(s), publisher and licensee Medip Academy. This is an open-access article distributed under the terms of the Creative Commons Attribution Non-Commercial License, which permits unrestricted non-commercial use, distribution, and reproduction in any medium, provided the original work is properly cited.

\section{ABSTRACT}

Background: Pain is one of the major discomfort which drives post caesarean mothers to seek help. Thus, it is important to know if any change in surgical technique could have effect on the post-operative pain which affects all the woman's activities. Hence, the study was undertaken to study the effect of closure and non-closure of parietal peritoneum on postoperative pain.

Methods: It was a hospital based interventional study done in a tertiary care hospital over one year. Detailed history, investigations, operative details, postoperative outcome in terms of pain were recorded and analysed.

Results: Women in the closure group had more postoperative pain. $\mathrm{P}$ value was highly significant at $8 \mathrm{~h}(\mathrm{P}=0.0001)$, 16h $(\mathrm{P}=0.0001), 24 \mathrm{~h}(\mathrm{P}=0.00001)$ and $32 \mathrm{~h}(\mathrm{P}=0.000001), 40$ hour $(\mathrm{P}=0.00001)$ and $48 \mathrm{~h}(\mathrm{P}=0.0001)$.

Conclusions: Peritoneal should not be closed routinely in caesarean sections as it is shown to cause less postoperative pain.

Keywords: Caesarean, Closure, Non-closure, Peritoneum

\section{INTRODUCTION}

Giving birth to a new life is one of the most painful experiences in a woman's life. Postoperative pain is one of the major discomforts which drives the caesarean mothers to seek help. The numbness around the incision and occasional aches and pains may last for several months. This interferes with mother infant interaction.

A small change in surgical technique affects various factors. Closure of peritoneum is traditionally done in all abdominal surgeries by suturing both the layers of peritoneum. ${ }^{1}$ Although the basic procedure remains same some newer techniques are being suggested like not closing the visceral and parietal peritoneum. If the peritoneum is not sutured and it results in better outcome to the patient then it would be easier for her to breastfeed the baby and be involved in new-born. ${ }^{2}$ It would also lead to reduction in mean operating time and suture material, which could lead to a meaningful cost saving, given the large numbers of caesarean sections performed worldwide. $^{3}$

Very few studies have been done in this part of the country on this issue, hence the present study was undertaken to find the association of peritoneal closure and postoperative pain. Mean duration of surgery was also noted.

\section{METHODS}

This was a hospital based interventional longitudinal study conducted in a tertiary care hospital from 1st February 2015 till 31st January 2016. Sample size was calculated at $80 \%$ study power and alfa error of 0.05 assuming standard deviation in Visual Analogue Scale 
(VAS) for pain of 1.48 as obtained in the study of Deshpande Hemant et al. ${ }^{1,4}$ For minimum detectable difference in mean Visual Analogue Scale (VAS) for pain of one, 36 patients in each group were required as sample size. It was further enhanced and rounded off to 40 patients in each group considering $10 \%$ attrition drop out.

Women aged 18-35 years, Body Mass Index (BMI) 18.5$24.99 \mathrm{~kg} / \mathrm{meter}$, primigravida with live singleton term pregnancy undergoing lower segment caesarean section under spinal anaesthesia and willing to give consent and participate in the study were randomly selected. Woman who had undergone any abdominal surgeries in the past, with polyhydramnios, severe anaemia, any sign of sepsis, hypertensive disease of pregnancy, active cardiac, renal, pulmonary, neurological or hepatic disease or on drugs that cause, sedation was excluded. Woman who had any intraoperative complications or postpartum haemorrhage were also excluded from the study.

Written informed consent was taken from all women for the surgery and to participate in the study. In both the groups, abdomen was opened by Joel Cohen technique. the caesarean section was done in a similar manner in all except that parietal peritoneum was sutured or left open according to the group allocation. Detailed records of intraoperative and postoperative parameters were made. Postoperative pain assessment was done by using visual analogue scale (VAS). ${ }^{4}$ Data collected was analysed. Pearson correlation coefficient and unpaired test were used for statistical significance and $\mathrm{P}$ value $<0.05$ was taken as significant.

\section{RESULTS}

The study comprised of two groups of forty women each. In group $\mathrm{A}$, the parietal peritoneal was closed with Chromic Catgut 1-0 and in group B, the parietal peritoneum was left open. Mean age, gestational age and Body Mass Index (B.M.I.) were comparable in both the groups. The average time for the surgery in the nonclosure group was shorter by more than two minutes as compared to the closure group and this difference was statistically significant (Table 1).

Table 1: Comparison of duration of surgery in the study groups.

\begin{tabular}{lll|l}
$\begin{array}{l}\text { Mean } \\
\text { duration of } \\
\text { Surgery }\end{array}$ & $\begin{array}{l}\text { Group A } \\
\mathbf{n}=\mathbf{4 0}\end{array}$ & $\begin{array}{l}\text { Group B } \\
\mathbf{n = 4 0}\end{array}$ & $\begin{array}{l}\text { Statistical } \\
\text { significance }\end{array}$ \\
$\begin{array}{l}\text { (In } \\
\text { minutes) }\end{array}$ & $\begin{array}{l}31.475 \pm \\
2.286\end{array}$ & $29.100 \pm 2.37$ & $\begin{array}{l}\mathrm{P}=0.00003 \\
\text { Highly } \\
\text { significant }\end{array}$ \\
\hline
\end{tabular}

Postoperative pain in women where the peritoneum was left open was less. The mean Visual Analogue Scale (VAS) for pain in the postoperative 48 hours was less in group B and the mean Visual Analogue Scale difference between the two groups was highly significant. (Table 2).
Table 2: Comparison of visual analogue pain score in the study groups.

\begin{tabular}{|llll|}
$\begin{array}{l}\text { Time } \\
\text { since } \\
\text { surgery } \\
\text { (hours) }\end{array}$ & Group A & Group B & $\begin{array}{l}\text { Statistical } \\
\text { significance } \\
\text { P value }\end{array}$ \\
\hline 8 & $8.29 \pm 1.77$ & $6.73 \pm 0.64$ & $0.0001(\mathrm{HS})$ \\
\hline 16 & $6.050 \pm 0.98$ & $5.28 \pm 0.55$ & $0.0001(\mathrm{HS})$ \\
\hline 24 & $5.20 \pm 1.50$ & $4.13 \pm 0.33$ & $0.00001(\mathrm{HS})$ \\
\hline 32 & $3.79 \pm 1.05$ & $3.00 \pm 0.82$ & $0.000001(\mathrm{HS})$ \\
\hline 40 & $2.16 \pm 0.92$ & $1.43 \pm 0.50$ & $0.00001(\mathrm{HS})$ \\
\hline 48 & $1.88 \pm 0.78$ & $1.53 \pm 0.51$ & $0.0001(\mathrm{HS})$ \\
\hline
\end{tabular}

Thus, the women in the non-closure group were more comfortable and could attend to their infant with ease.

There was no positive correlation of pain score with other factors like age (Table 3) and Body Mass Index (Table 4).

Table 3: Correlation of postoperative VAS score with age.

\begin{tabular}{|lll|}
\begin{tabular}{|l} 
Age \\
(in years)
\end{tabular} & $\begin{array}{l}\text { Mean VAS score } \pm \text { SD at 24hours } \\
\text { postoperatively } \\
\text { Group A }\end{array}$ & Group B \\
\hline $18-22$ & $6.21+1.27$ & $4.10 \pm 0.31$ \\
\hline $23-27$ & $6.33+1.82$ & $4.06 \pm 0.25$ \\
\hline$>27$ & $6.33=1.36$ & $4.25 \pm 0.50$ \\
\hline R value & $0.279(\mathrm{NS})$ & $0.0957(\mathrm{NS})$ \\
\hline
\end{tabular}

Table 4: Correlation of VAS score with BMI.

\begin{tabular}{|lll|}
\hline & $\begin{array}{l}\text { Mean VAS score at 24hours } \\
\text { postoperatively }\end{array}$ \\
Body Mass & Group A & Group B \\
Index $\left(\mathrm{kg} / \mathrm{m}^{2}\right)$ & $\begin{array}{l}\text { N=40 } \\
\text { n=40 }\end{array}$ & Mean \pm SD \\
& Mean \pm SD & $4.15 \pm 0.36$ \\
\hline$<22$ & $6.69 \pm 1.31$ & $4.07 \pm 0.26$ \\
\hline$>22$ & $5.58 \pm 1.44$ & $-0.1554(\mathrm{NS})$ \\
\hline R Value & $0.0749(\mathrm{NS})$ & \\
\hline
\end{tabular}

\section{DISCUSSION}

In the study, the mean duration of surgery was significantly less than the closure group. This reduces the duration of anaesthesia and exposure of wound to external environmental contaminants, thus decreasing the risk of anaesthetic complication, wound infection and thromboembolic complications. ${ }^{5}$ It also leads to the more efficient use of theatre time and reducing the total cost. Noreen Sarwat et al in their also found decrease operating time when the peritoneum was left open during caesarean sections. $^{6}$ However, in the CAESAR study and CORONIS Trial, they found no differences in duration of caesarean section in the two groups. ${ }^{7,8}$ The difference in mean VAS score between peritoneal closure and nonclosure group taken at 24 hours postoperatively was 
highly significant in the study. Peritoneum is a highly sensitive epithelial lining and responds strongly against any foreign material, releasing many pain mediating cytokines and interleukin causing increased postoperative pain. Suturing the peritoneum stimulates foreign body reaction in the peritoneum resulting in peritoneal inflammation and ultimately increased postoperative pain. In addition, clots collected in the closed peritoneal space behind uterovesical fold could be a factor for postoperative pain in peritoneal closure groups. ${ }^{9}$ Kurek Eken M, et al and Agarwal $\mathrm{N}$ et al also found pain to be significantly more in closure groups than non-closure groups. ${ }^{10,11}$ In the CORONIS trial however, there was no significant difference in the postoperative pain. ${ }^{8}$

In our study the mean VAS score was compared between different age groups. Pearson correlation coefficient was used. The mean VAS score at 24 hours was taken for correlation. We observed that though mean VAS score was statistically significant in all the age groups between closure and non-closure group, there was no significant change in the mean VAS score within different age groups. Thus, age had no correlation with the pain score. The VAS score was also compared between two groups BMI $<22$ and $>22$. Pearson correlation coefficient was used. The mean VAS score at 24 hours was taken for correlation. Thus, BMI seemed to have no effect on the mean VAS score.

\section{CONCLUSION}

To conclude, if the parietal peritoneum in caesarean section is left open it results in less postoperative pain. The duration of surgery is lesser resulting in better patient outcome. This is also significantly cost effective.

\section{Funding: No funding sources}

Conflict of interest: None declared

Ethical approval: The study was approved by the Institutional Ethics Committee

\section{REFERENCES}

1. Deshpande H, Burute SB, Madkar CS, Dahiya P. The effect of suturing and non-suturing of visceral and parietal peritoneum on postoperative pain in caesarean section. Int J Pharm Biomed Sci. 2012, 3(4);164-6.

2. Arias F, Bhide AG, Arulkumaran S, Damania K, Daftary SN, editors. Practical guide to high risk pregnancy and delivery. Elsevier health sciences; 2012.

3. Bamigboye AA, Hofmeyr GJ. Closure versus nonclosure of the peritoneum at caesarean section. Cochrane Database of Systematic Review; 2007.

4. Mehack R, Torgerson WS. On the language of pain. Anaesthesiol. 1971;34(1):50-9.

5. Tabasi Z, Mahdian M, Abedzadeh-Kalahroudi M. Closure or non-closure of peritoneum in cesarean section: outcomes of short-term complications. Arch Trauma Res. 2013;1(4):176.

6. Noreen S, Alam M, Khan WY, Sultana R, Gul SA comparison of peritoneal closure with non-closure for short term morbidity in emergency lower segment cesarean section KJMS. J. 2015; 8(1):76-9.

7. The CAESAR study collaborative group. Caesarean section surgical techniques: a randomised factorial trial (CAESAR). BJOG 2010;117:1366-76.

8. Group TC. Caesarean section surgical techniques (CORONIS): a fractional, factorial, unmasked, randomised controlled trial. 2013; 382(9888):234-48.

9. Fahmy MM, Saleh SA, Khouly NIE, Zahrane RA. Short-term effect of closure versus non-closure of peritoneum at cesarean section. Life Sc J. 2015;12(2)60-3.

10. Kurek Eken M, Özkaya E, Tarhan T, İçöz Ş, Eroğlu Ş, Kahraman ŞT, Karateke A. Effects of closure versus non-closure of the visceral and parietal peritoneum at cesarean section: does it have any effect on postoperative vital signs? A prospective randomized study. J Maternal-Fetal Neonatal Medicine. 2016:1-5.

11. Agarwal N. Agarwal BK. Effect of non closure of peritoneum on outcome of caesarean Section - a prospective randomised control study. IJSR - Int J Sci Res. June 2015;806-17.

Cite this article as: Sharma A, Hooja N, Shastri A, Dadhich B, Manish R. Evaluation of postoperative pain in closure versus non-closure of parietal peritoneum at caesarean section. Int J Reprod Contracept Obstet Gynecol 2017;6:1969-71. 